\title{
NATURALEZA Y DISTRIBUCIÓN ESPACIAL DE LOS GRABADOS RUPESTRES DEL NORTE DE LA PENÍNSULA DO BARBANZA (A CORUÑA)
}

\author{
"Nature and spatial distribution of the prehistoric petroglyphs in \\ the Northern side of the Barbanza Peninsula"
}

\author{
Ramón Fábregas Valcarce, Carlos Rodríguez Rellán y Emilio Rodríguez Álvarez* \\ Recibido el 14 de noviembre de 2007. Aceptado el 10 de enero de 2008
}

\begin{abstract}
Resumen. La investigación realizada en el área de Porto do Son (Península do Barbanza, A Coruña) se ha basado en una intensiva labor de campo y en el análisis reiterado de las estaciones, incluyendo revisiones diurnas y nocturnas. Esta aproximación ha permitido incrementar el conocimiento sobre el emplazamiento del arte rupestre al aire libre, mostrando que las mayores concentraciones de petroglifos se sitúan en las alturas medias de las estribaciones serranas. A su vez, el descubrimiento de estaciones en las proximidades de la costa y, sobre todo, de grabados en el interior de abrigos rocosos, enriquece la casuística sobre la distribución espacial de este fenómeno. Por otra parte, la revisión de estaciones ya catalogadas permitió documentar nuevos motivos, muchos de los cuales, como armas o laberintos, eran prácticamente desconocidos en esta área.

Palabras clave: Petroglifos. Localización. Barbanza. Arte rupestre. Reutilización de los grabados.
\end{abstract}

Abstract. The research carried out about the rock art in the Northern side of the Barbanza Peninsula (Porto do Son, A Coruña) has been based on an intensive survey, together with a thorough review of the carved surfaces under natural and artificial light conditions. This approach has allowed us to increase both the number of the sites and also the iconographic variety of those previously known. As to the spatial distribution, we have found that the densest clusters of petroglyphs occur in the intermediate slopes between the coastal plain and the sierra. Some exceptions to this trend are noticeable, either in carved rocks found close to the sea or others near the highest points of the study area. Other findings worth noting are the petroglyphs retrieved inside two rock shelters (a very rare feature indeed in the Galician prehistoric art), the increase in the number of representations of metallic weapons and the first occurrence of a labyrinth.

Key Words: Rock art. Site location. Barbanza Peninsula. Petroglyph's afterlife.

Hacia finales de los 80, el profesor Ripoll insistió en repetidas ocasiones a uno de los firmantes de este trabajo (R.F.V., en aquel entonces doctorando suyo), en el interés que tenía el estudio del arte rupestre galaico, un comentario que durante algún tiempo cayó en saco roto. Una serie de favorables circunstancias, entre las que se cuenta la invitación a formar parte de un proyecto de investigación junto a R. Bradley y F. Criado, luego continuado en una serie de trabajos con el primero de los autores, nos condujo final- mente a la senda investigadora señalada por tan insigne especialista en el arte prehistórico de la Península lbérica y que en la actualidad conforma ya un buen número de publicaciones y proyectos, como el que a continuación vamos a resumir en sus líneas principales, que deseamos constituya un merecido homenaje al Dr. Eduard Ripoll i Perelló.

Desde hace cuatro años se ha venido desarrollando en el Norte de la Península do Barbanza (A Coruña) una intensa labor de análisis en el campo del arte rupestre prehistórico a 


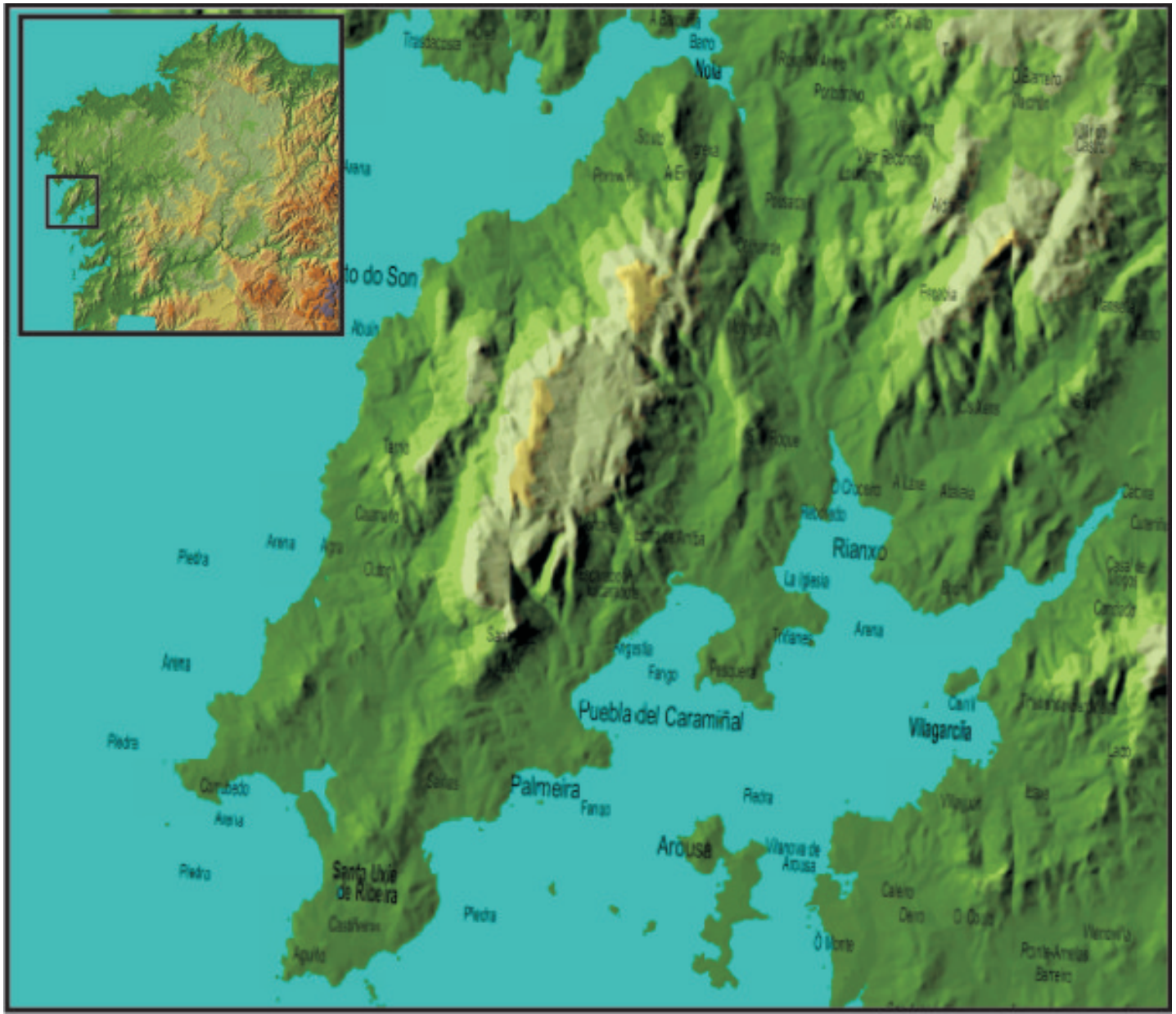

A Figura 1. Mapa de situación de la Península del Barbanza.

través de las investigaciones realizadas por el GEPN (Grupo de Estudios para a Prehistoria Recente do Noroeste) ${ }^{1}$ de la Universidad de Santiago de Compostela. Dichos trabajos, unidos a la labor previa realizada tanto por arqueólogos como por investigadores aficionados, han supuesto la eclosión definitiva de este punto de la costa atlántica como un área en la que el fenómeno rupestre alcanzó una importancia e identidad propias, que convierten a la Península do Barbanza en un núcleo sobresaliente dentro del fenómeno del arte rupestre galaico y no una mera periferia del centro principal de estas manifestaciones, situado en Campolameiro (Pontevedra).

La Península do Barbanza constituye un área geográfica bien delimitada y consolidada (fig. 1), estableciéndose como la más septentrional de las penínsulas que encuadran las denominadas "Rías Baixas", ubicándose entre las rías de Arousa (al Sur) y de Muros-Noia (al Norte). Aquella puede ser dividida en dos grandes unidades topográficas que, a su vez, definen sendos espacios de una enorme variabilidad bio- geográfica. Por un lado se encuentra la sierra, que forma un núcleo montañoso escasamente poblado, con una altitud media de $550 \mathrm{~m}$ y que sirve como divisoria de aguas entre las rías mencionadas. Por otra parte existe una plataforma costera que alterna playas, arenales y acantilados rocosos tras los cuales se extiende una estrecha llanura litoral (que se expande en determinados lugares), con unas características ecológicas muy diversificadas, pero en la que se concentran las tierras de mayor profundidad donde actualmente se ubican las zonas de asentamiento y cultivo.

No obstante, debemos tener en cuenta que el paisaje que contemplamos en la actualidad es el resultado de una prolongada acción antrópica que, junto con procesos de origen natural, ha supuesto una importante actividad erosiva especialmente en las zonas más altas y en las laderas más pronunciadas, actualmente formadas por rocas desnudas. Además, poseemos bastantes indicadores que apuntan hacia cambios significativos en la delineación de la línea cos-

(1) Incluidas en el proyecto de investigación «Ocupación do Espacio e Modificación do Entorno na Península do Barbanza durante a Prehistoria Recente, os petroglifos de Porto do Son" financiado por el Ministerio de Ciencia y Tecnología y por los incentivos de la Consellería de Innovación, Industria e Comercio (Dirección Xeral de Investigación e Desenvolvemento) de la Xunta de Galicia. 
tera durante los últimos 5.000 años. Estudios realizados en otras áreas de la Península do Barbanza, como la laguna de Carregal (Ribeira), la playa de Ladeira (Boiro), o la Punta de Pericos (Ribeira) sugieren importantes modificaciones en la línea de costa que afectaron a la configuración de las dunas y a los complejos lacustres (Vilas et al.,1991; Fábregas y Ruiz Gálvez, 1997; Fábregas, 2001). El movimiento de dunas y arenales, relativamente frecuente en estos lugares, además de otros fenómenos geológicos sumados a los procesos que acabamos de definir, han cambiado sustancialmente el paisaje en el que se movían los grupos humanos en el momento del grabado de las estaciones.

\section{LA INVESTIGACION: PRECEDENTES Y METODOLOGÍA}

El arte rupestre de la Península do Barbanza ha suscitado el interés de los investigadores desde antiguo. Así, las primeras referencias a los petroglifos de esta zona se retrotraen a los años 20 del siglo pasado cuando F. López Cuevillas y F. Bouza Brey (1927-28) recogen, en una obra sobre la prehistoria y el folklore de la zona, varias estaciones de la comarca. Después de esos primeros pasos habrá que esperar varias décadas hasta que los investigadores vuelvan a fijar su atención en el Barbanza. X. Agrafoxo (1986) realiza un estudio en el que se recogen noticias de petroglifos en la Península do Barbanza pero, al igual que sus insignes predecesores, tampoco se hace eco de la presencia de grabados en la parte más septentrional de dicha península. A mediados de la década de los 90 del pasado siglo, con el trabajo de los arqueólogos A. Concheiro y D. Gil (1995), que dan a conocer varios conjuntos en Porto do Son, por fin se hará notar la presencia de grabados prehistóricos en la vertiente Norte de la Serra do Barbanza. En esta misma época, M. J. Soto y J. Rey (1994) publican en detalle otra gran superficie, la de Laxe da Sartaña.

A partir de esa fecha se sucede una serie de inestimables labores de prospección del terreno que dan a conocer un número ingente de nuevas estaciones que cambian, en apenas cinco años, la percepción que, sobre este territorio y su importancia en el contexto gallego se tenía hasta ese momento y acabarán por convertir a la Península do Barbanza en un importante núcleo de arte rupestre. Un primer trabajo sería el de M. Mariño (2000) y, sobre todo, el de J. Guitián y X. Guitián (2001) donde ya se inventarian 56 estaciones con arte rupestre, número que se vio incrementado en los últimos años hasta casi un centenar de superficies, gracias a las exploraciones realizadas por estos mismos investigadores.

A estos trabajos se le suma, a partir del 2002, la investigación realizada por el GEPN que, en colaboración con los mencionados especialistas, completa el actual inventario, que supera las 130 estaciones. La actuación de nuestro grupo se limita al ayuntamiento de Porto do Son, el cual se constituye como el límite norte de la Península do Barbanza. Con el fin de realizar un análisis sistemático del área de estudio, se compartimentó la misma en dos sectores diferenciados entre sí por la intensidad de la exploración que en ellos se llevaría a cabo, una vez ejecutado un estudio previo en el que se incluyó el recorrido previo de la zona, recogida de información sobre estaciones previamente conocidas, encuestas orales, etc.

La primera de las zonas, que comprende la mayor parte del área de estudio, es aquella en la que se realizó un análisis extensivo del terreno sometiéndose a una revisión detaIlada aquellos lugares con un mayor interés debido a la presencia de petroglifos ya catalogados o a la existencia de masas rocosas susceptibles de haber sido grabadas en la prehistoria, así como también aquellos lugares considerados que, por su delineación fisiográfica, pudieron haber jugado un papel importante dentro de los parámetros de movilidad de las poblaciones prehistóricas (collados o áreas naturales de tránsito). La segunda de las áreas demarcadas fue aqueIla en la que el análisis del terreno tendría una naturaleza intensiva; dicha zona se situó en la parroquia de San Pedro de Baroña (fig. 2). Dada la concentración e importancia de las estaciones conocidas en este lugar se realizó una prospección "de cobertura total", centrada en el Monte de Gurita en el que se efectuó un reconocimiento integral de los afloramientos y otros puntos de interés arqueológico en busca de nuevos grabados.

Debido a la especial importancia que supone disponer de una buena luz para la correcta observación y comprensión de las estaciones con grabados, la metodología aplicada se centró en la realización de reiteradas y exhaustivas inspecciones de los petroglifos a distintas horas del día, complementadas eventualmente con revisiones mediante luz artificial. De este modo, se pudo establecer con un alto grado de fiabilidad, la naturaleza de las representaciones conservadas en cada una de las estaciones. Sólo tras estas observaciones iniciales, se procedió al calcado de los grabados en láminas de plástico transparente posteriormente digitalizadas y nuevamente cotejadas con el propio petroglifo.

\section{EL ARTE RUPESTRE EN EL NORTE DE LA PENÍNSULA DO BARBANZA}

La aplicación durante los trabajos de campo de unos criterios metodológicos bien definidos ha permitido el descubrimiento de nuevas estaciones $y$, sobre todo, motivos inéditos en rocas conocidas desde hace años e incluso estudiadas anteriormente por especialistas. Además del análisis formal de las estaciones, se hizo especial hincapié en la recogida de información concerniente al estado de conservación de los motivos y, sobre todo, de datos relacionados con las condiciones de emplazamiento y el entorno de las estaciones (relación con las vías de tránsito y con otros yacimientos, visibilidad del entorno, vegetación y pedregosidad del terreno circundante, profundidad del suelo, etc.). 


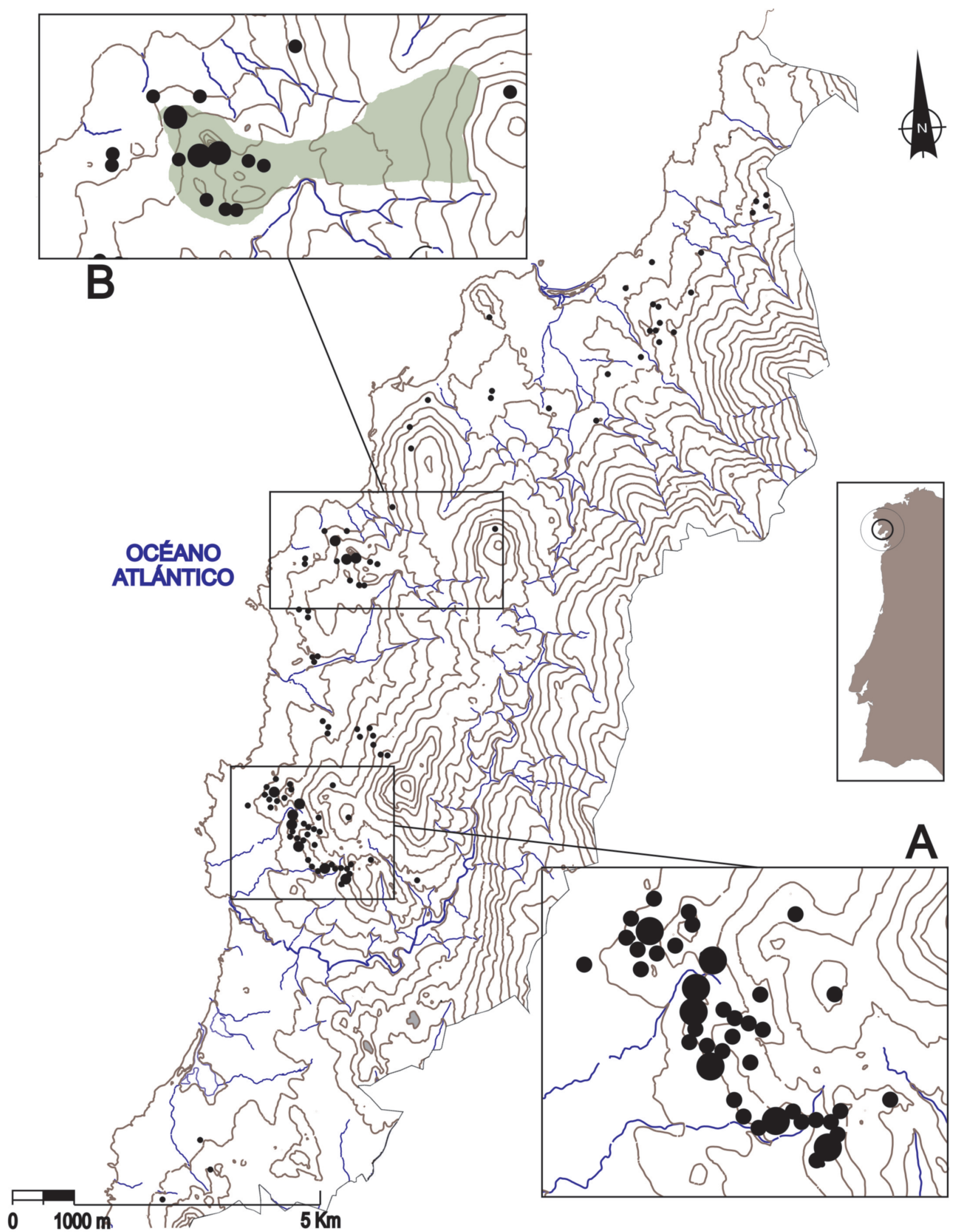

A Figura 2. Ubicación de las estaciones conocidas en la zona de estudio. A) Grupo de estaciones de Campo Grande/Campelos. B) Área de cobertura total y prospección intensiva en el Monte de Gurita (Baroña). 


\subsection{Distribución espacial}

Uno de los primeros elementos que llama nuestra atención a la hora de estudiar la distribución de las estaciones es la aparente concentración de las mismas en alturas medias (de 51 a 200 m.s.n.m.) (fig. 3) produciéndose una fuerte caída en el número de rocas con grabados en aquellas cotas de menor y mayor altitud. Según esto, los petroglifos parecer haber sido grabados preferentemente en lo que podriamos denominar "zona intermedia" entre las dos grandes áreas del territorio a las que nos referíamos al comienzo de este artículo: la sierra y la plataforma costera.

Como no podía menos que esperarse, hay varias estaciones que no se amoldan a este parámetro general de distribución, incrementando así la riqueza y variabilidad de la ubicación de los petroglifos en esta zona. Uno de estos casos es la estación de Basoñas (Fábregas et al., 2007), situada apenas a 15 m.s.n.m. y a muy poca distancia de la costa. Junto a éste existe algún que otro caso aislado de petroglifos a baja cota en la Península do Barbanza, a los que se suman recientes descubrimientos en las inmediaciones del propio Basoñas. En el extremo opuesto se encuentran una serie de estaciones situadas a considerable altitud, incluso en lo alto de la sierra a más de $350 \mathrm{~m}$. La mayoría de estos petroglifos están compuestos por cazoletas, aisladas o en pequeños grupos y casi siempre relacionadas con monumentos megalíticos. También existe, sin embargo, un caso excepcional de un motivo más complejo localizado a considerable al- tura, se trata de la combinación circular de Bugina Grande, situada a 425 m, en la ladera NO del Monte Enxa.

Además de esta compartimentación de los petroglifos por altura, la observación del emplazamiento fisiográfico de las estaciones del Norte del Barbanza (fig. 4), permite entrever una ubicación mayoritaria de las mismas en laderas y vertientes intermedias ( $45 \%$ ), en lugares con mayor dominio visual de las Ilanuras costeras. Dicha localización resulta mucho más frecuente que otras, a priori más idóneas, tales como dorsales (19\%) y collados (6\%), lugares tradicionalmente vinculados al tránsito. Por otra parte, el análisis de la inclinación de las rocas que sirven como soportes a los petroglifos (fig. 5) evidencia un claro dominio de las superficies planas o de escasa pendiente (menores de $30^{\circ}$ ), las cuales aparecen en un 65 $\%$ de los casos, mientras que las superficies verticales (mayores de $60^{\circ}$ ) tan sólo suponen un $3 \%$ del total.

Dicho dominio de los paneles planos, en los que los motivos se pierden de vista a escasos metros de la roca, unida a la mencionada preferencia por las laderas sobre zonas de tránsito como dorsales y collados, hace que no se pueda hablar para el caso de la Península do Barbanza, al menos de modo general, de que los petroglifos habrían funcionado como marcadores en el paisaje destinados a ser vistos desde las cercanas rutas de paso sino como elementos que, en cierto sentido, se encuentran cerrados sobre sí mismos.

Ese aparente carácter críptico de muchas de las estaciones alcanza su máxima expresión en un nuevo tipo de ubicación de los grabados que, hasta el momento, era inédito en la

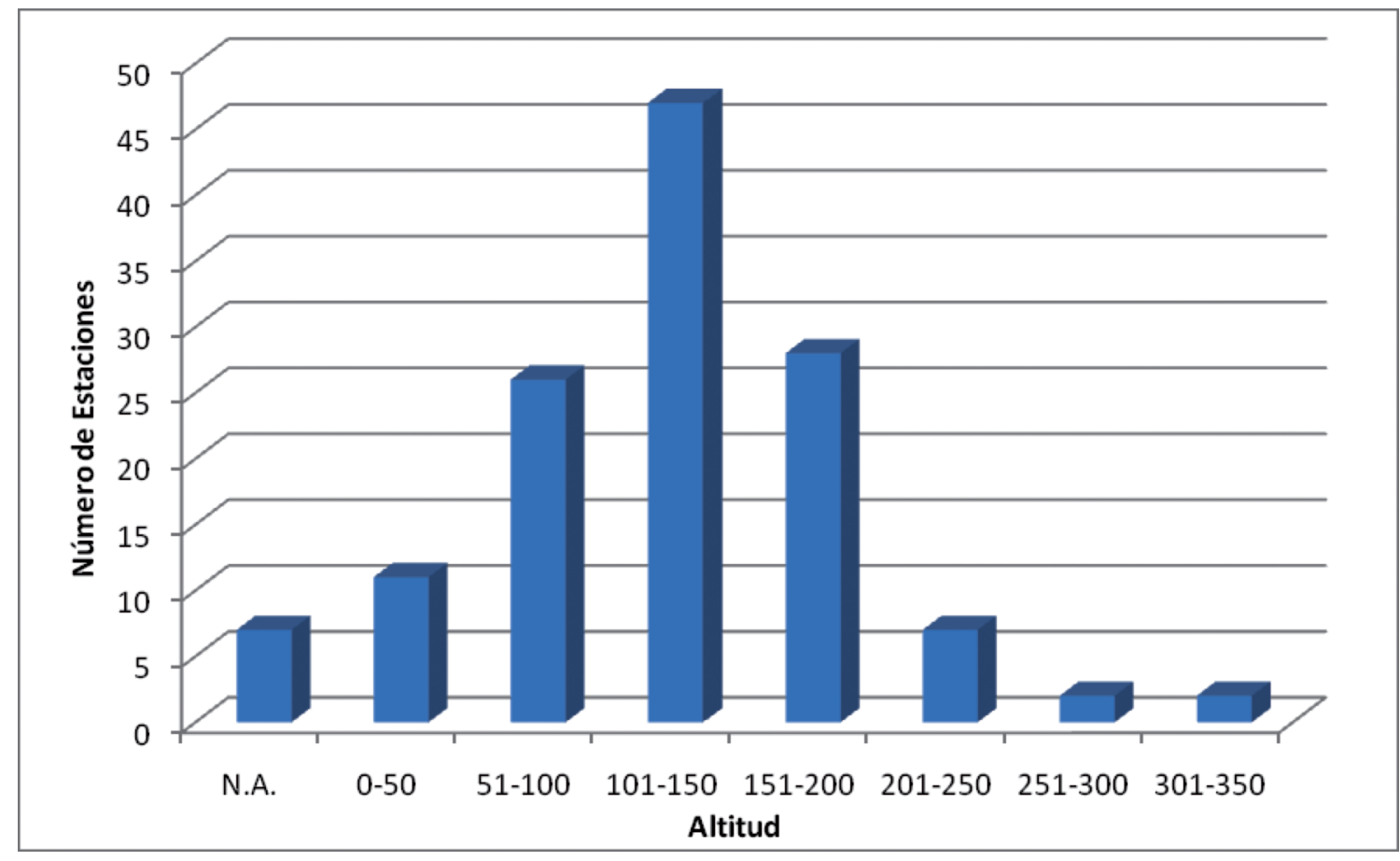

- Figura 3. Distribución de petroglifos por tramos de altitud sobre el nivel del mar. 


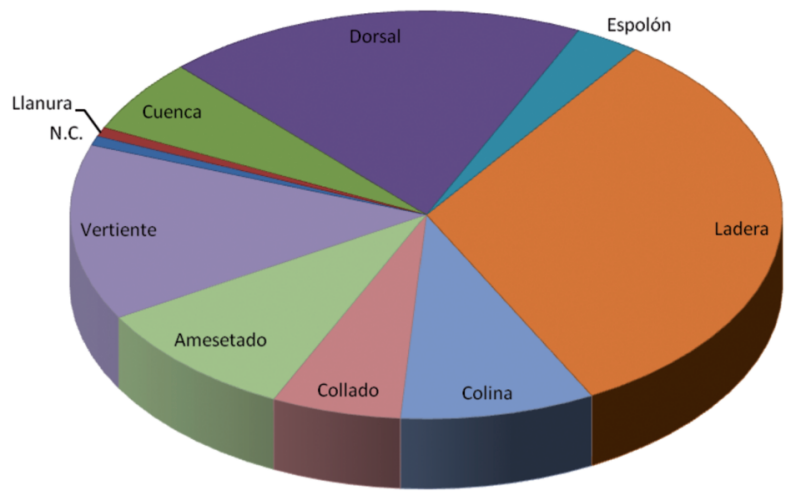

FigURA 4. Distribución de petroglifos según su emplazamiento fisiográfico.

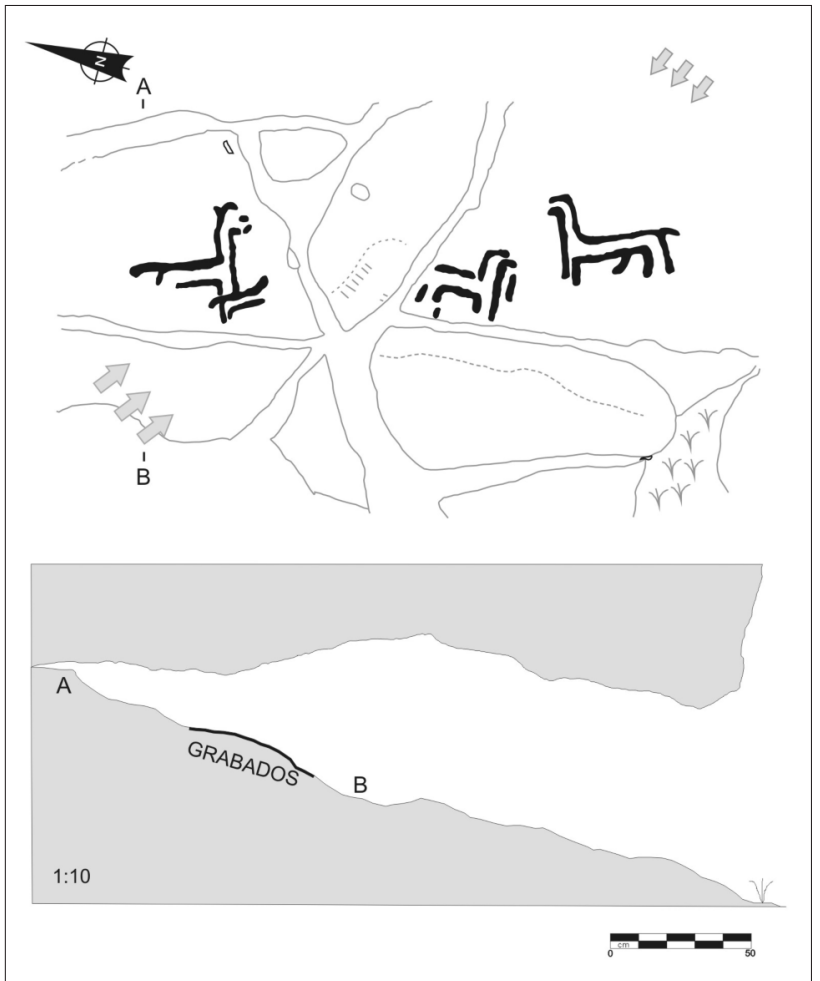

A Figura 6. Abrigo de Rego de Corzo (Caamaño).

Peninsula do Barbanza: los abrigos rocosos. Un primer ejemplo es el "Abrigo do Rego de Corzo", donde, en una grieta existente entre dos batolitos graníticos, se grabaron cuatro zoomorfos (fig. 6). El otro caso es el del "Abrigo de Calderramos" (fig. 7), en donde se documentó la existencia de una combinación circular así como cazoletas y varios surcos que en la actualidad se encuentran, en parte, al aire libre debido a la

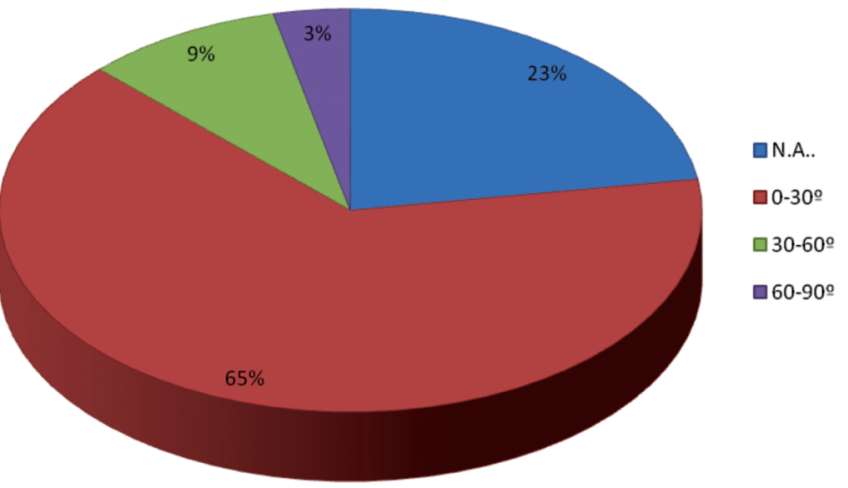

FiguRA 5. Distribución de petroglifos según la inclinación de los paneles.

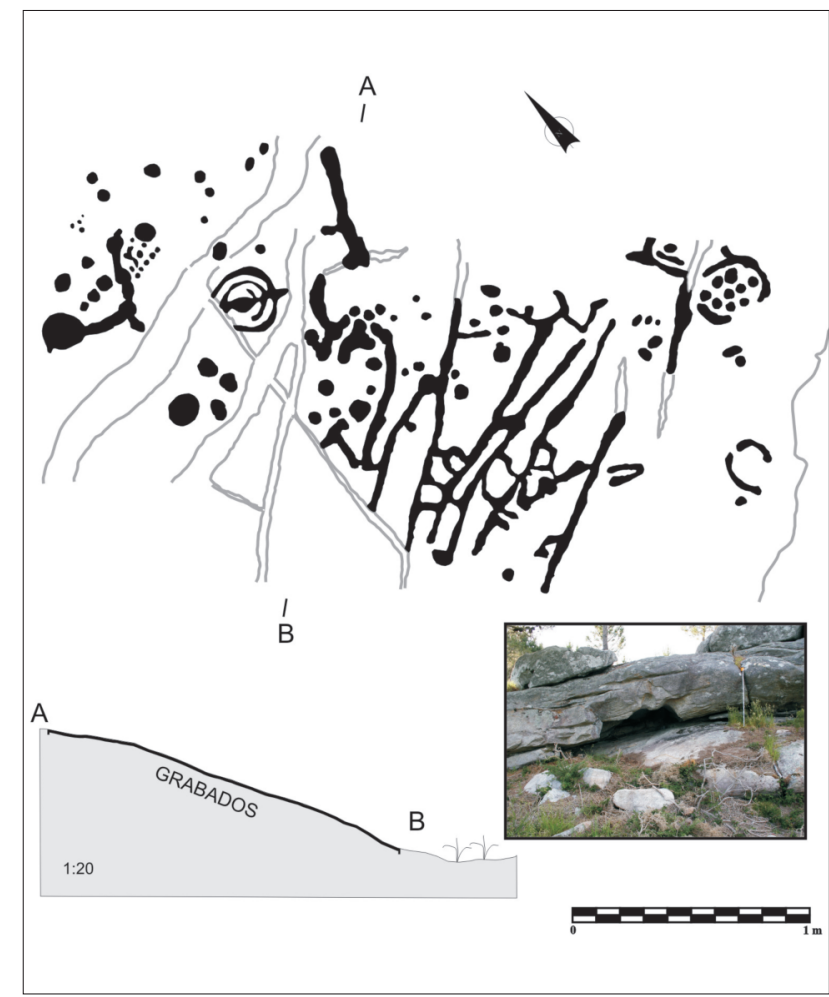

A Figura 7. Abrigo de Calderramos (Baroña). Vista general de la entrada del abrigo.

destrucción parcial por canteros de la visera. En ambos casos, se trata de lugares de reducidas dimensiones, situados en la zona de media ladera y muy cerca de cursos de agua a los cuales dominan en altura, donde apenas existiría espacio para uno o, a lo sumo, dos individuos y en los que los motivos sólo serían visibles de un modo claro mediante iluminación artificial (sobre todo en el caso del Abrigo de Calderramos). 


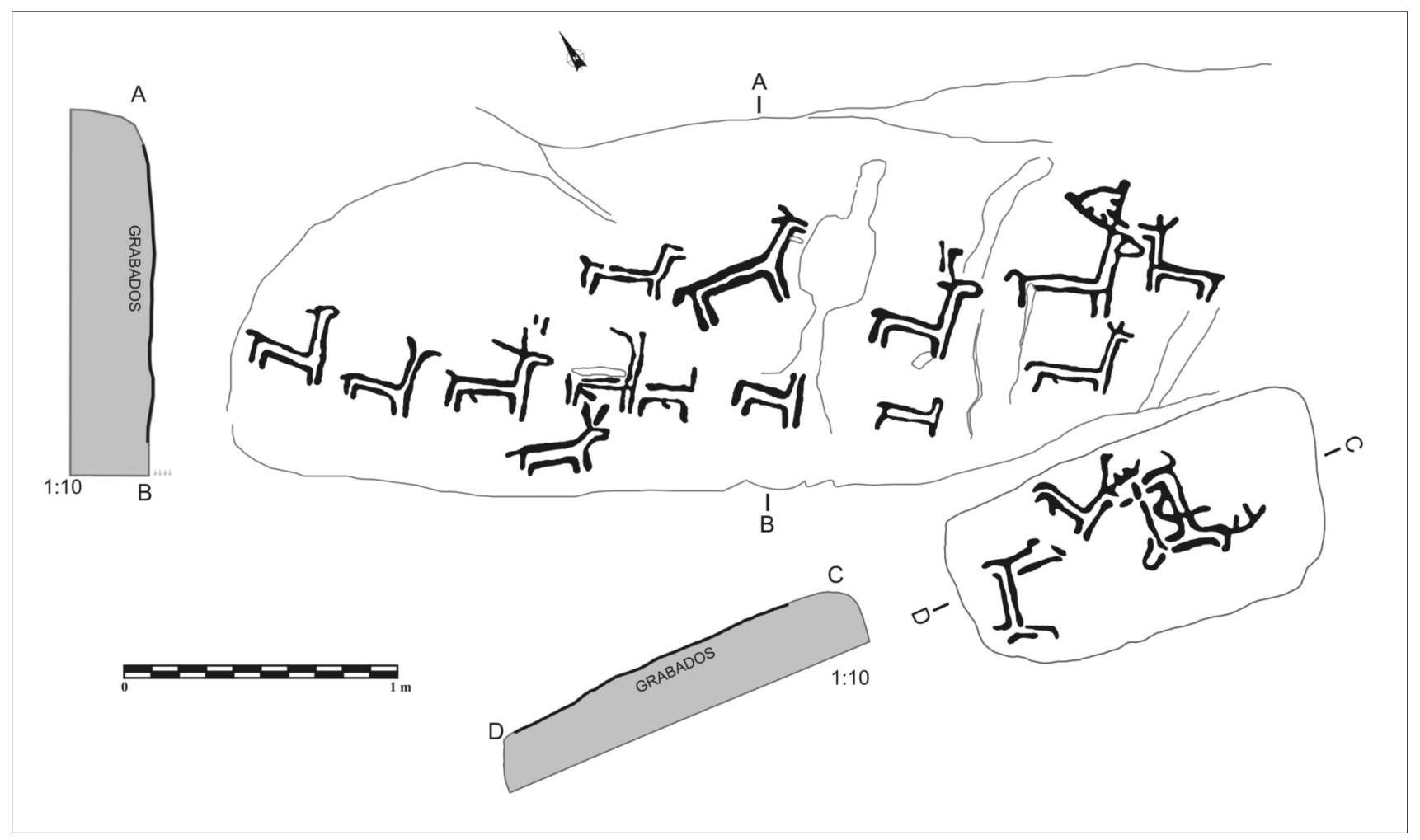

A Figura 8. Estación de Pozas da Garda (Noal).

Este carácter cerrado puede verse incluso en muchos paneles que, por su inclinación vertical, parecen estar hechos para ser vistos. Éste es el caso, por ejemplo, de estaciones como Pozas da Garda u Outeiro Bicudo (figs. 8 y 9). Dichos grabados, sin embargo, no se sitúan en zonas de fácil acceso y tránsito natural desde los que los motivos serían fácilmente visibles sino que, por lo general, se hallan por debajo de las mismas; estas dos estaciones tampoco se encuentran en lugares especialmente propicios para el ascenso hacia puntos más altos, dada la fuerte pendiente del terreno circundante. Por lo tanto no es descabellado afirmar que pudo haber existido una preferencia por lugares conspicuos desde los que se ejerciese un dominio visual "a larga distancia" sobre la plataforma costera, antes que otros desde los que se tuviese un control inmediato sobre lugares de tránsito.

Justo es decir, no obstante, que esta naturaleza aparentemente críptica no es común a todas las estaciones, existiendo casos claros de paneles verticales incluidos en zonas de paso desde las que los motivos serían fácilmente visibles, como es el caso de Outeiro Campelos I y Campogrande I, ambos a poca distancia entre sí. Estos forman parte de una de las áreas con mayor densidad de grabados de la Península do Barbanza, sita en la parroquia de Caamaño, en la parte central del Ayuntamiento de Porto do Son (fig. 2). En este lugar, las alturas intermedias (de los 90 a los $150 \mathrm{~m}$ ) de la ladera SO de las estribaciones de la sierra se encuentran dominadas por grandes masas graníticas en las que se ha documentado un total de 66 estaciones en una superficie de apenas $2 \mathrm{~km}^{2}$.

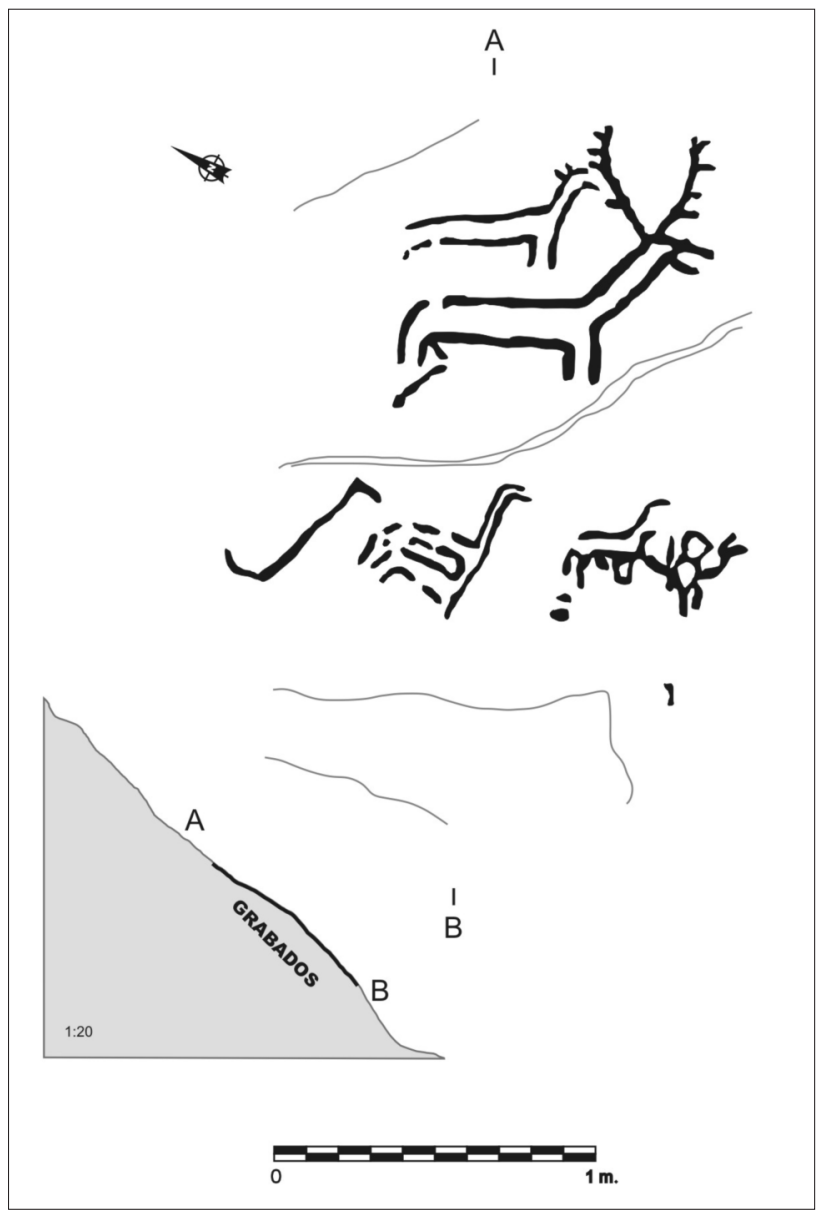

- Figura 9. Estación de Outeiro Bicudo I (Baroña). 


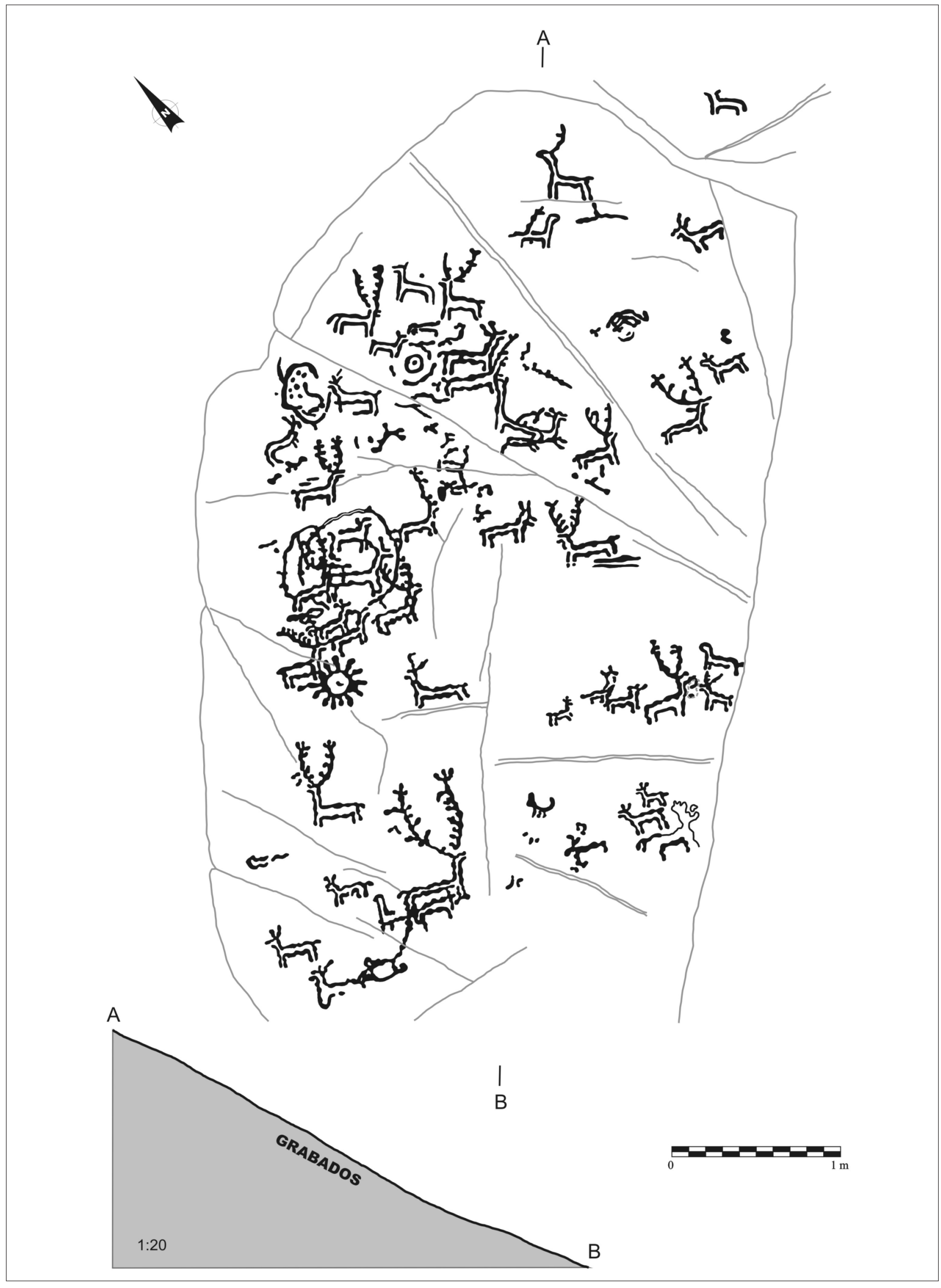

A Figura 10. Estación de Gurita I (Baroña). 
Esta concentración se emplaza precisamente frente a uno de los puntos del Norte de la Península donde la plataforma costera alcanza una mayor anchura. Dicha llanura se encuentra además regada por el río Sieira, uno de los más grandes y caudalosos de la zona, cuyo valle abre una vía de paso hacia las tierras del interior. Asimismo, dentro de esta concentración, parece existir una gran densidad en torno a los cursos superiores de dos de los afluentes (fig. 2A) que este río tiene por el Norte. Por último, esta zona supone uno de los mejores lugares para el ascenso hacia lo alto de la dorsal que supone las estribaciones de la Serra do Barbanza.

Una situación parecida ocurre con una segunda concentración documentada gracias a las labores de prospección. Dicha acumulación de petroglifos se sitúa en la falda meridional del Monte de Gurita (fig. 2B), en la parroquia de Baroña, lugar donde se realizó la prospección de cobertura total. En las estribaciones de este monte se conocía un total de 9 petroglifos, entre ellos Gurita I (fig. 10) que, con más de medio centenar de representaciones zoomorfas y un motivo solar único en el grupo de arte rupestre galaico, se constituye como la estación de mayor complejidad de toda la zona. Los trabajos realizados por el GEPN, permitieron aumentar el número de estaciones hasta un total de 22, estableciéndose así como la segunda área de mayor densidad de petroglifos del Norte de la Península do Barbanza. Al igual que en el caso anterior, dicha concentración se sitúa en las inmediaciones de un punto donde la llanura costera incrementa su anchura y en las cercanías de un curso de agua, prácticamente seco en la ac- tualidad (pero del que aún se conservan topónimos reveladores como Cova do Rego o Lama Trema). También como en la parroquia de Caamaño, estos petroglifos se sitúan en una de las subidas más cómodas hacia el alto de la dorsal.

Además de la constatación de zonas con una gran acumulación de petroglifos, la prospección extensiva nos ha permitido documentar varias rocas con grabados en zonas que, hasta el momento, se consideraban marginales. Éste es el caso del extremo suroccidental del Ayuntamiento de Porto do Son, donde se evidenció la existencia de dos estaciones de considerable importancia, como es el caso de un motivo estilo "Peña Tú" en el ya mencionado panel de Basoñas (fig. 11) o una superficie con zoomorfos, al menos un antropomorfo y un reticulado asociado a un cérvido en Monte da Pedreira (fig. 12). Además de los referidos, la aparición de una serie de petroglifos en la parte Norte y SE del Ayuntamiento permite completar la visión sobre la distribución del arte rupestre en la vertiente Norte del Barbanza y superar la existencia de falsos vacíos en su localización.

\subsection{Los motivos}

El arte rupestre de la Península do Barbanza presenta unas características muy similares, en cuanto a tipología de los motivos grabados, a las de los núcleos paradigmáticos de la parte Sur de Galicia (Campo Lameiro, Cotoba de,...). En este sentido, podemos observar la notable importancia del grupo naturalista, presidido por las representaciones de animales

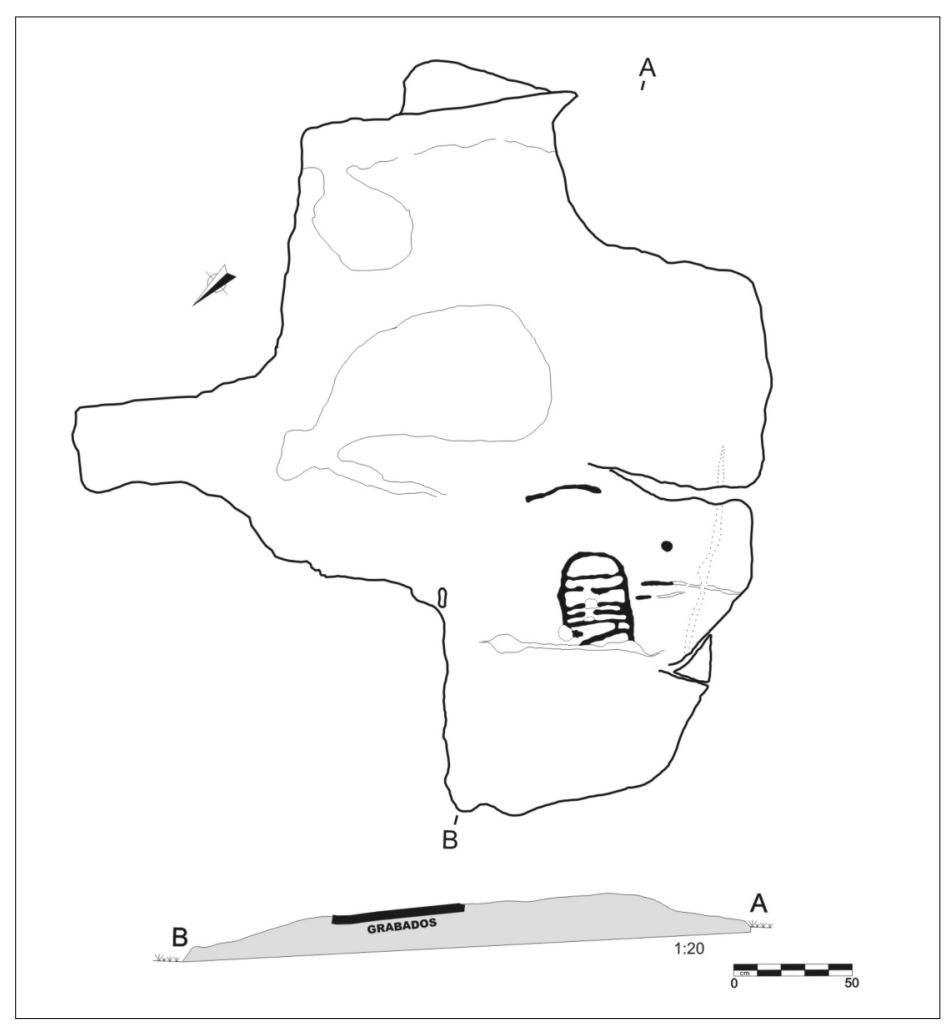

- Figura 11. Estación de Basoñas (Muro).

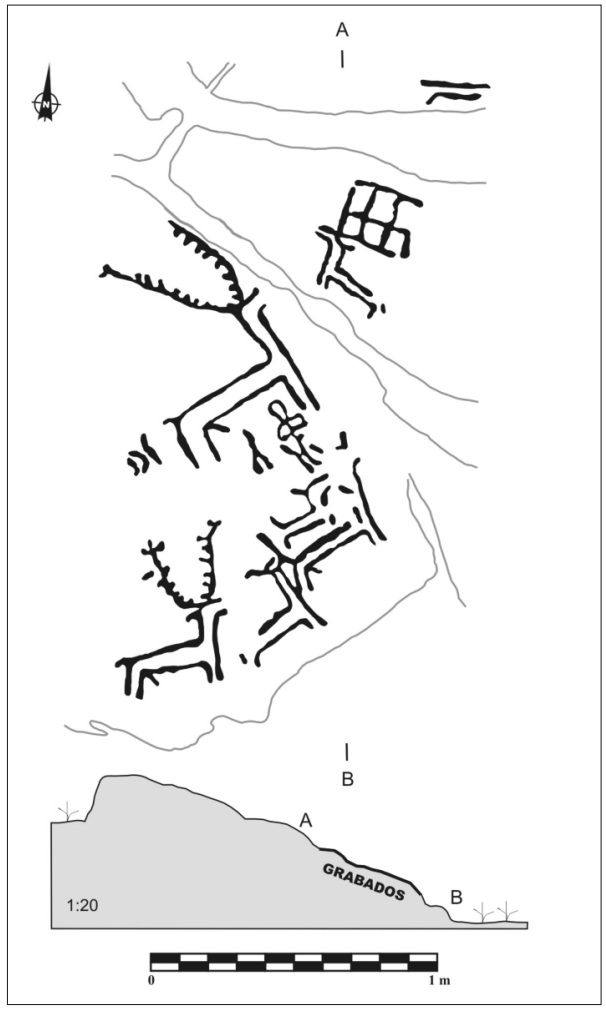

A Figura 12. Estación de Monte da Pedreira (Muro). 


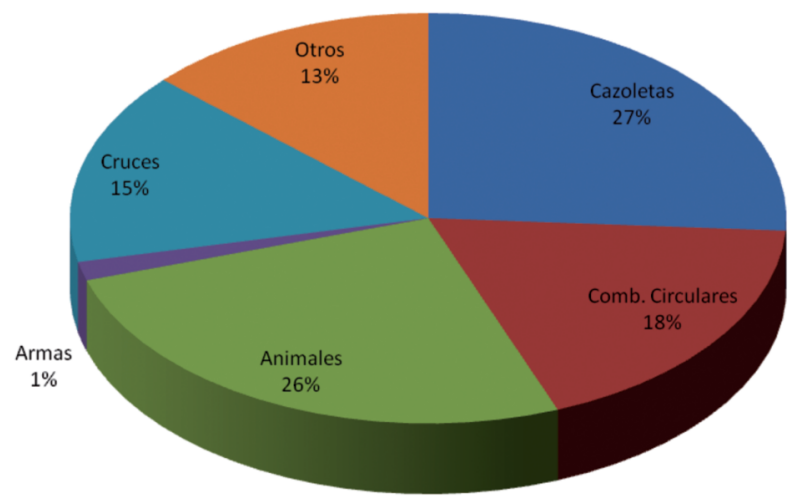

A Figura 13. Distribución de los petroglifos según la tipología de sus motivos.

(fig. 13) que se encuentra en segundo lugar, tras las estaciones pertenecientes al grupo geométrico, conformado por cazoletas y combinaciones circulares. Por último, las armas y otros motivos como cruces y tableros de juego apenas superan la docena de estaciones.

Dentro del grupo naturalista predominan de un modo absoluto los cérvidos, representados normalmente de modo estático, con o sin cornamenta. Además de este tipo de zoomorfos contábamos, hasta el momento presente, con la representación de tan sólo una figura equina, montada por un jinete, y -posiblemente- de algún cánido, todos ellos formando parte de una supuesta escena cinegética en la estación de Laxe da Sartaña (Soto y Rey, 1994). Otro tipo de

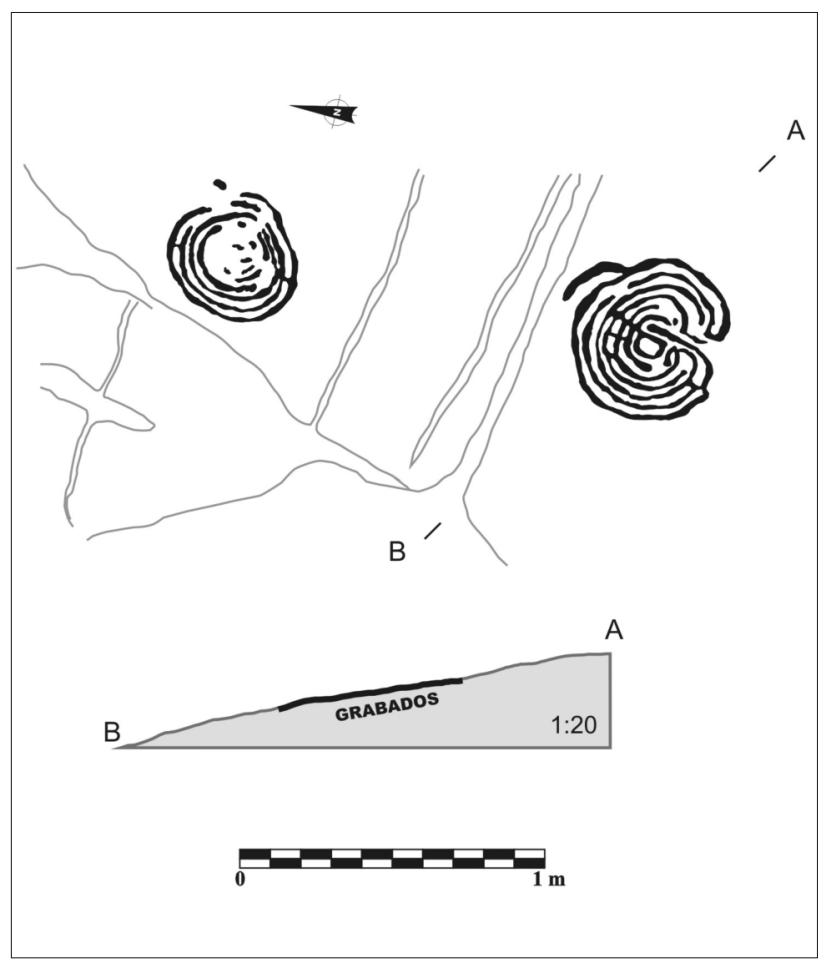

A Figura 14. Estación de Laxieles (Noal). representaciones naturalistas son las armas, de las cuales se conocía, hasta ahora, un solo ejemplo en la Península do Barbanza (el puñal de Espiñaredo I) (Guitián y Guitián, 2001). El grupo abstracto o geométrico, por su parte, está compuesto mayoritariamente por cazoletas y combinaciones circulares. Entre estas últimas, destacan de modo casi exclusivo los círculos concéntricos, documentándose tan sólo un motivo en espiral (en la estación de Beira da Costa).

El trabajo de campo sistemático de los últimos años ha enriquecido el catálogo de motivos del grupo rupestre de la Península do Barbanza con nuevos motivos, entre los cuales uno de los más significativos es la representación de tipo "Peña Tú" documentada en Basoñas (fig. 11), cuya aparición conecta esta área del occidente galaico con un grupo temático que ve su expansión en la cornisa cantábrica y el norte de Portugal. Al carácter extraordinario del motivo debemos sumarle la ubicación de la roca que, como ya afirmamos en el apartado anterior, se encuentra a una altura inusualmente baja y muy cerca de la costa. Otro tema inédito hasta ahora es el de los laberintiformes, del cual se documentó un ejemplar en la estación de Laxieles (fig. 14). En el catálogo de las novedades también debemos destacar la presencia de un reticulado vinculado a un zoomorfo en la estación de Monte da Pedreira (fig. 12) y de los que teníamos contados ejemplos en Galicia, entre ellos el de Cova da Bruxa (Muros, A Coruña).

Sin embargo, resulta importante ante todo el incremento de motivos de los que apenas se conocía un sólo ejemplo en toda la comarca y que ahora se han visto multiplicados. Un caso especialmente significativo es el del grupo de las armas,

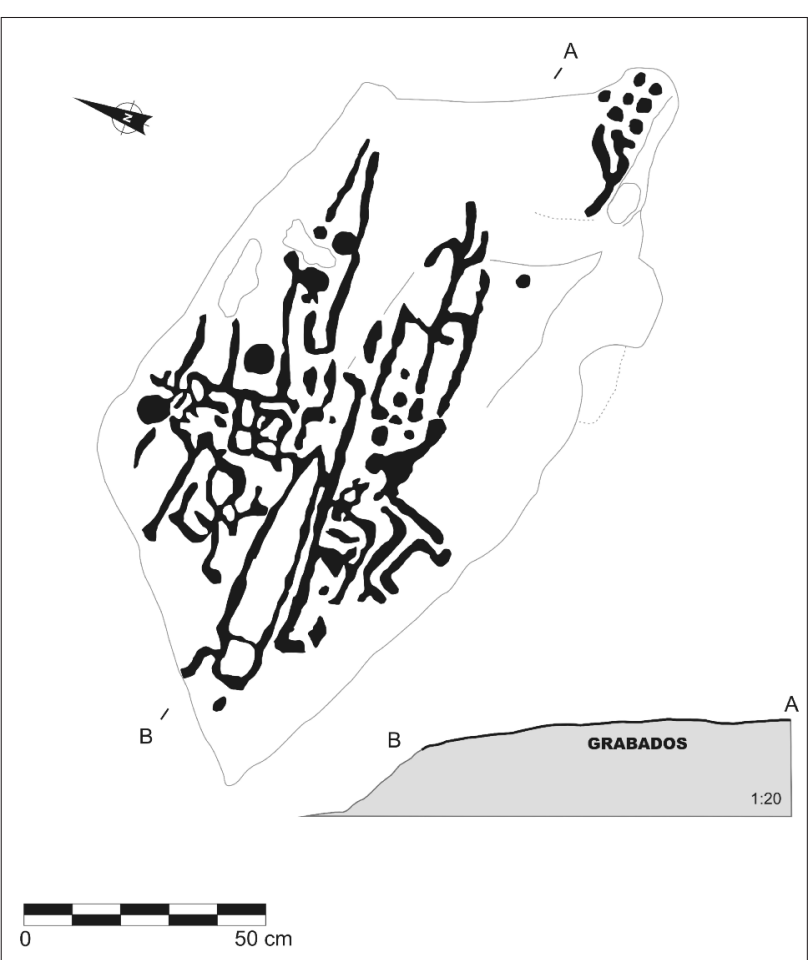

A Figura 15. Estación de Beira da Costa IV (Caamaño). 


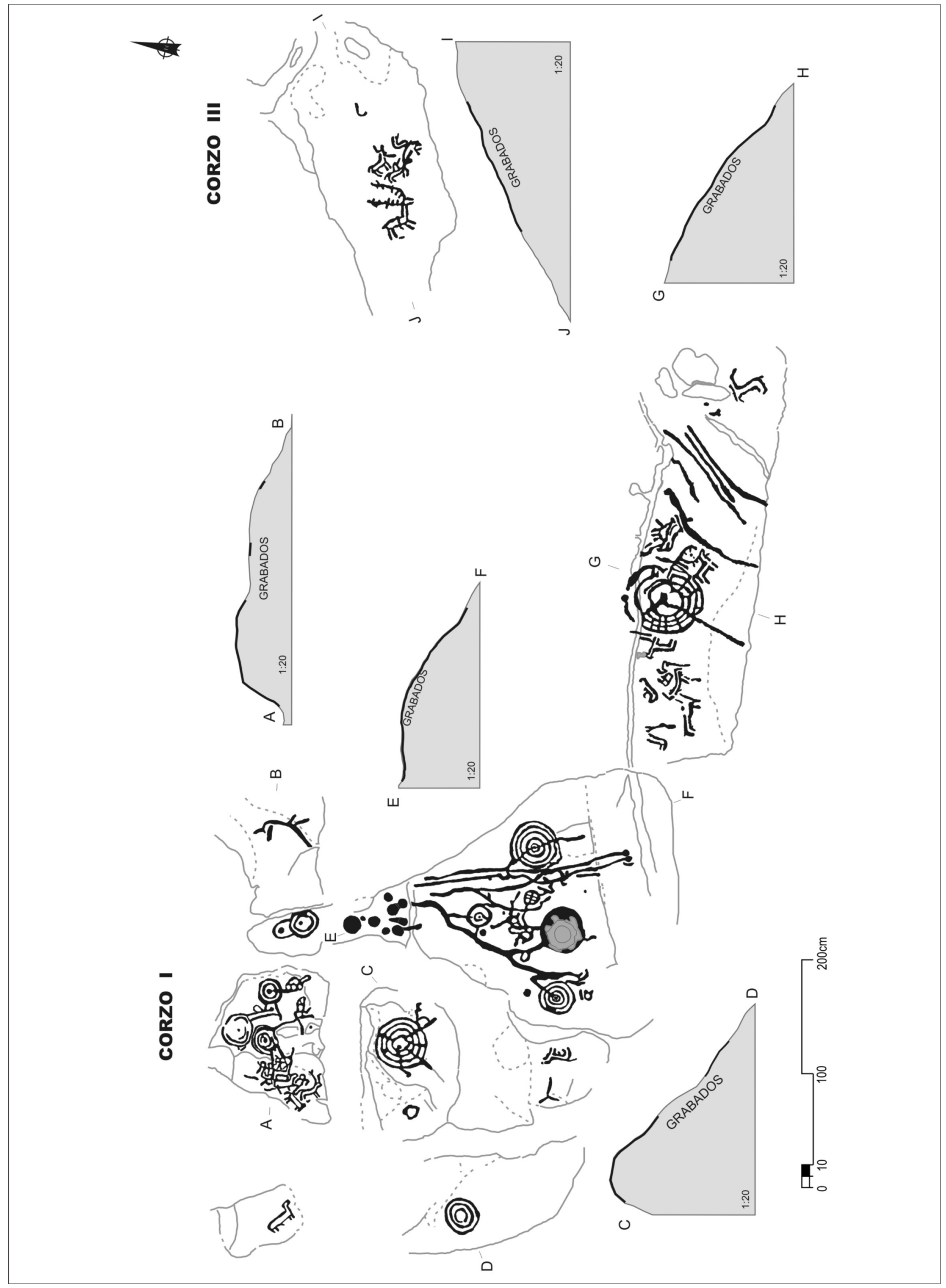

A Figura 16. Estación de Rego de Corzo I y III (Caamaño). 


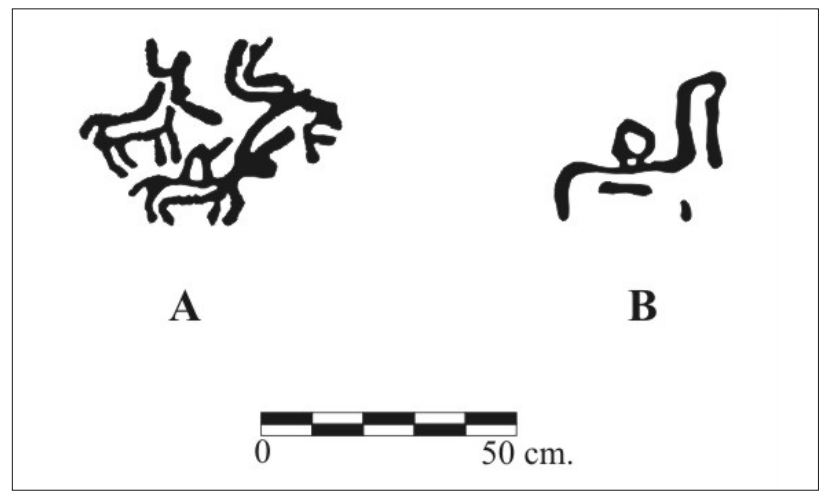

A Figura 17. Escenas de monta de Rego de Corzo III y Outeiro Campelos III.

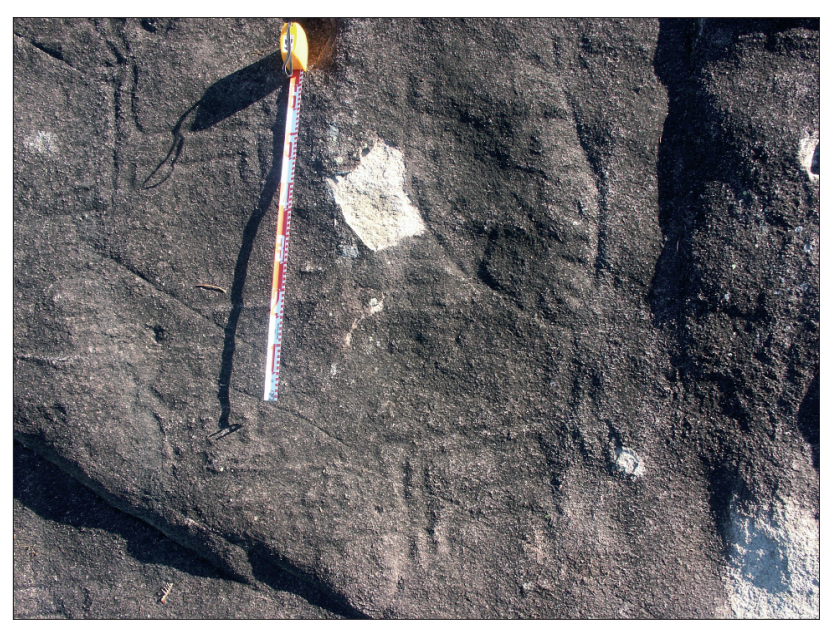

A Figura 18. Desconchado de Gurita I provocado por los incendios forestales.

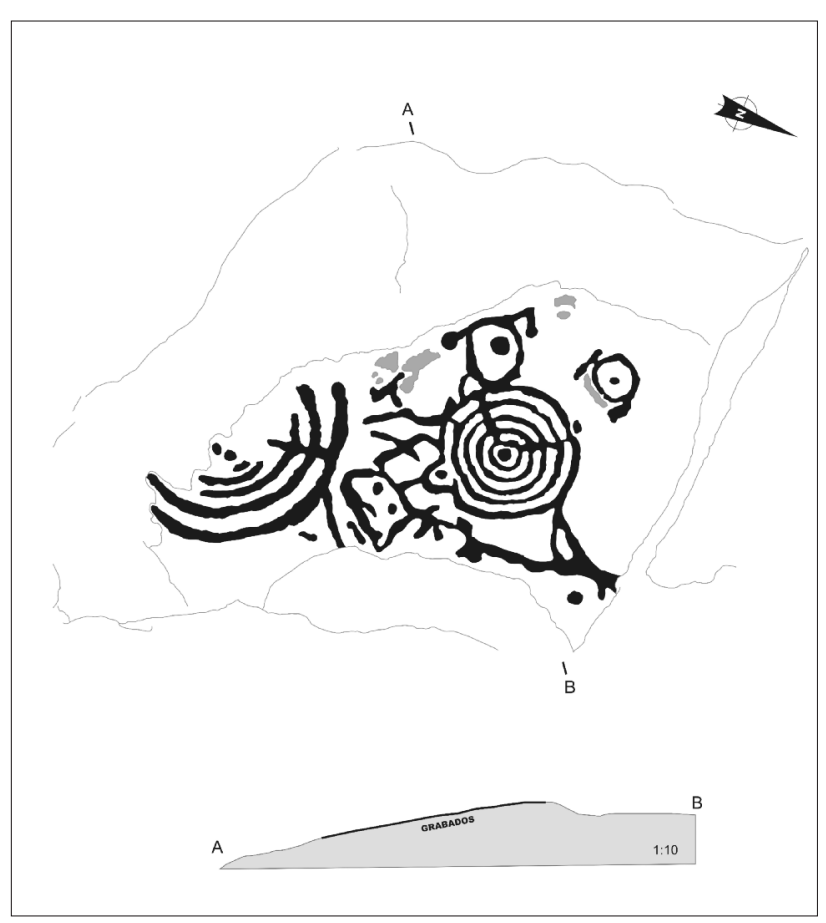

- Figura 19. Estación de A Picota (Miñortos) parcialmente destruída por la estracción de piedra. que de una pasa a tener cuatro representaciones. De éstas, las dos primeras se ubican en la estación de Espiñaredo IV, a tan sólo unos metros por encima del único ejemplar previamente conocido. Esta roca, en la que anteriormente sólo se habían documentado varios zoomorfos, ha proporcionado un puñal así como una posible representación de un cuchillo metálico de tipo Vilanova de Saõ Pedro. Otros dos puñales se localizaron en una roca de pequeñas dimensiones, Beira da Costa IV, acompañados por zoomorfos y cazoletas (fig. 15).

Otro conjunto que se ha visto ampliamente modificado ha sido el de los antropomorfos. Si hasta el momento tan sólo se conocía una representación claramente prehistórica de la figura humana en la Península do Barbanza: la de la escena de monta de Laxe da Sartaña, tras las prospecciones y revisiones de los paneles se han documentado varios ejemplos más. Uno de los más espectaculares es el de Outeiro Bicudo I (fig. 9) donde, en la parte inferior de un panel totalmente vertical anteriormente conocido por sus grandes zoomorfos, se localizó un antropomorfo formando parte de una escena de doma en la que éste aparece unido a un animal por medio de lo que parece ser una soga. Junto con este ejemplar, es de destacar la presencia de varios posibles antropomorfos como el de Monte da Pedreira (fig. 12), situados -al igual que en el caso anterior- a los pies de un gran animal o aquellas figuras posiblemente humanas que forman parte de lo que pudiera ser una escena junto con varios zoomorfos en el sector NW. de Rego de Corzo (fig. 16 y 21). Inmediatamente al sur de la Serra do Barbanza, destacamos el conjunto de Os Mouchos (Rianxo) (fig. 24) en el que, de nuevo, encontramos antropomorfos, uno de ellos de grandes dimensiones, en un panel con abundantes imágenes de cérvidos. Además de los citados, podríamos incluir aquellas imágenes en las que zoomorfos y antropomorfos aparecen en relación directa: nos referimos a las escenas de monta de las que, además de la de Laxe da Sartaña, se han documentado dos nuevos ejemplos como son el de Rego de Corzo III o el de Outeiro Campelos III (fig. 17).

El mencionado aumento ha permitido ampliar la casuistica de los motivos, permitiendo establecer relaciones entre figuras pertenecientes a los distintos grupos. En este sentido, algunos autores (Santos, 2005) habían otorgado cierta significación cronológica al hecho de que la única representación de armas de la zona (Espiñaredo I) apareciese de un modo aislado. Sin embargo, la existencia de nuevos casos en los que este tipo de motivos comparten panel con zoomorfos o cazoletas parece invalidar dicha hipótesis, tanto más cuanto que la revisión de Espiñaredo I nos llevó a localizar restos de dos cérvidos en el mismo panel en el que se ubica un puñal, así como un zoomorfo de gran cornamenta en actitud de movimiento a escasos seis metros del mismo. En suma, en la totalidad de las representaciones de armas documentadas en la Península do Barbanza existe una relación directa entre éstas y otras figuras como animales o cazoletas. 


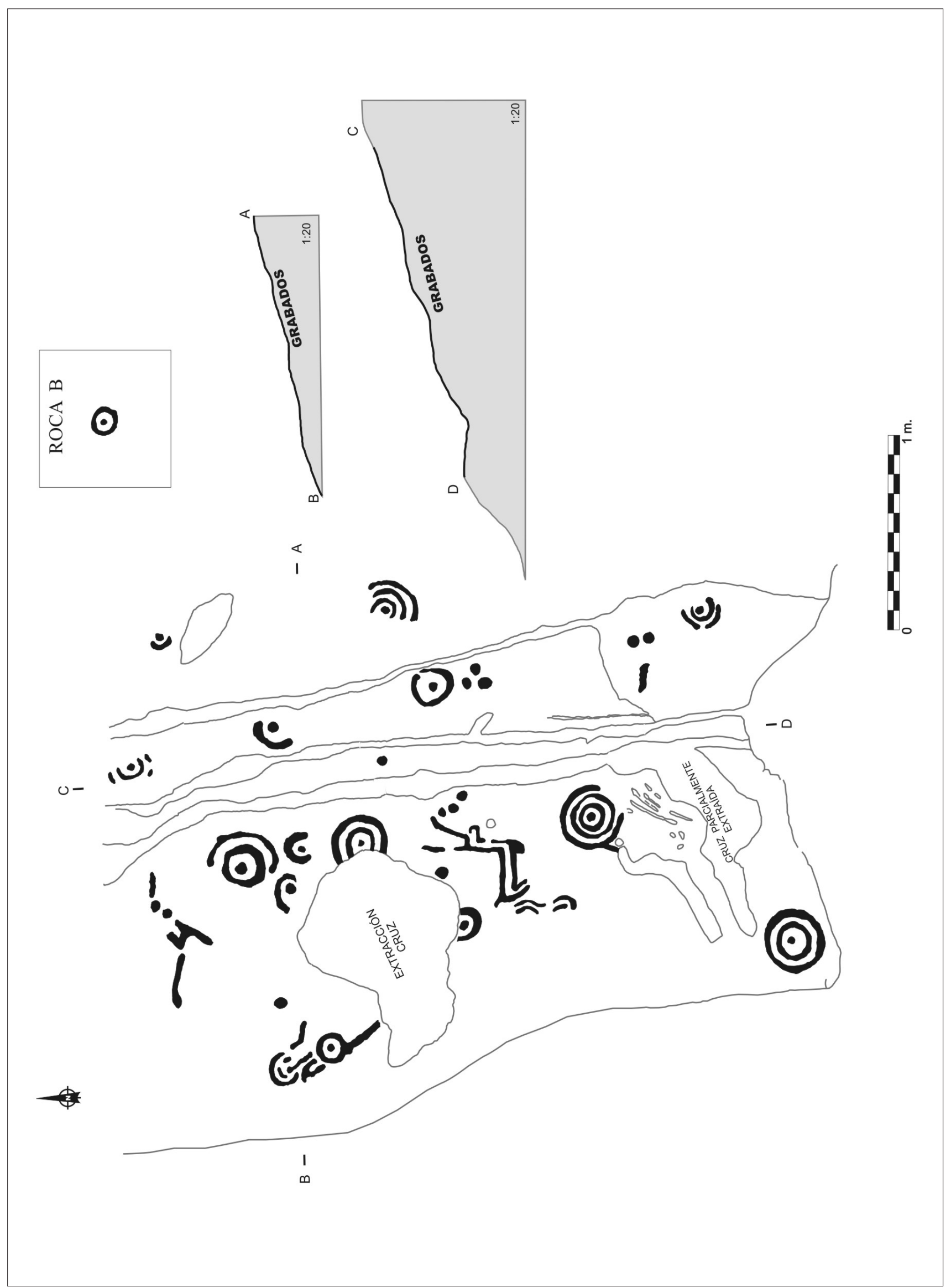

A Figura 20. Estación de Gurita IV (Baroña). 


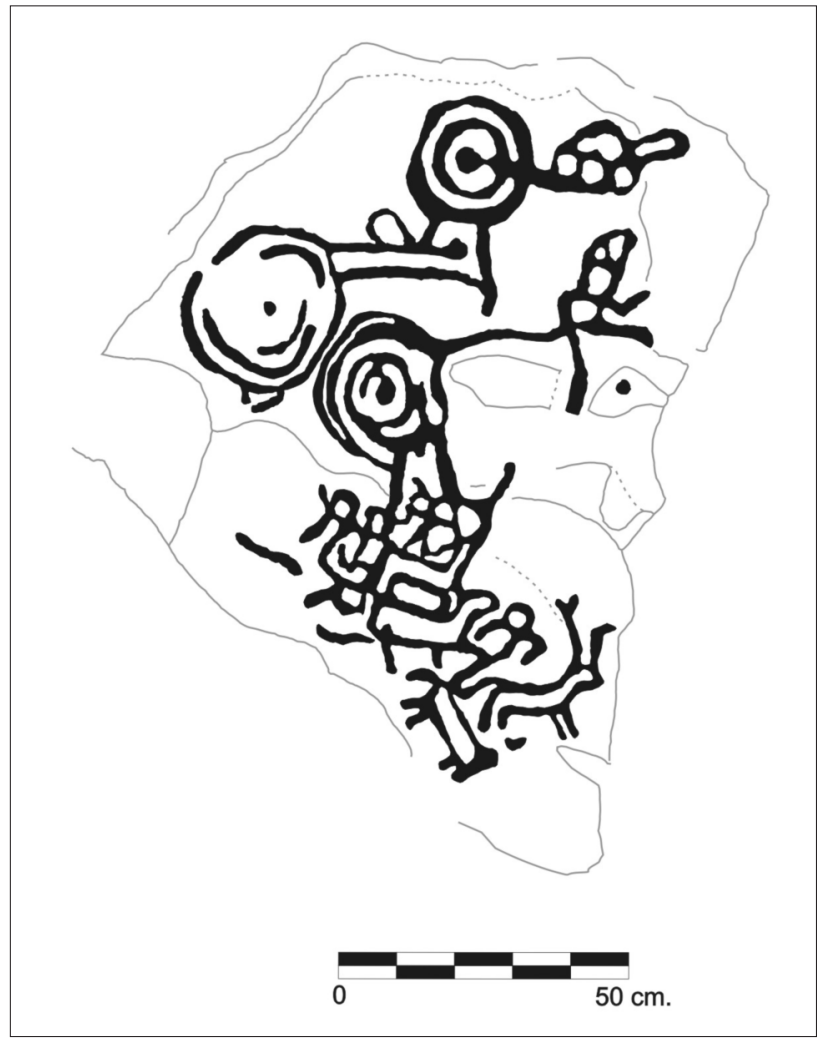

A Figura 21. Detalle de la posible composición de Rego de Corzo I.

Creemos que estos nuevos hallazgos deben permitirnos superar la visión de pobreza que acompañaba al conjunto rupestre de la Península do Barbanza y especialmente de su sector norte. Por otra parte, el descubrimiento de gran número de motivos en rocas previamente conocidas y estudiadas no hace más que señalar la necesidad de una revisión intensiva de las estaciones, en la que los reiterados análisis con luz natural y artificial juegan un papel fundamental. De no ser así, se corre el peligro de una visión incompleta de los paneles $y_{1}$ en consecuencia, de efectuar una interpretación limitada o errónea de los mismos. Dicho trabajo deberá ser realizado, en nuestra opinión, en el marco de actividades de investigación que no se vean excesivamente limitadas por el tiempo y los medios disponibles, como ha solido suceder hasta ahora.

\section{3. ¿“DEL PASADO EFIMERO”?. DESTRUCCIÓN Y MODIFICACIÓN DE LOS PANELES RUPESTRES}

Los petroglifos, como elementos inmersos en el medio natural, han experimentado cambios a lo largo del tiempo al mismo ritmo que el entorno circundante, viéndose afectados, al igual que él, por acciones tanto de origen natural como humano. Estos episodios han incidido sobre las estaciones de un modo más o menos intenso, alterándolas en su aspecto e incluso suplantando su significado original. A menudo estas alteraciones son simplemente producto del paso del tiempo, cuya acción hace que, en algunos casos, sea difícil determinar la existencia de grabados debido al deficiente estado de conservación de las superficies. En otros casos estos fenómenos, casi siempre contemporáneos, se ven acompañados de otro tipo de procesos más intensos que llegan a destruir la roca por completo.

El conocimiento de las dinámicas de destrucción que afectan a los petroglifos es, si cabe, mucho más necesario en el área en la que se ha realizado el estudio dado que en la misma se está llevando a cabo un desarrollo urbanístico muy intenso y un abandono de los modos de vida tradicionales, que han convertido a los montes en masas de maleza, donde se producen periódicamente virulentos incendios forestales que ponen en serio peligro la conservación de los grabados. Consideramos pues, que sólo la elaboración de una carta de riesgos puede proporcionarnos las herramientas necesarias para garantizar la protección de esta parte del patrimonio histórico de Galicia. Por ello, hemos sentido la necesidad de recoger información acerca del grado de afectación general de las estaciones, así como el tipo de alteración más frecuente a la que éstas se han visto sometidas.

En este sentido, la inspección del estado de los paneles ha evidenciado de un modo claro que los fenómenos que más profundamente han afectado al arte rupestre del área de estudio han sido los incendios forestales y la labor de los canteros. La acción del fuego ha provocado multitud de desconchados por termoclastia, decoloraciones de la roca e incluso la pulverización de la misma, afectando gravemente a los motivos en ellas grabados. Lamentablemente, los incendios se han venido repitiendo periódicamente durante los meses estivales de los últimos años, de tal modo que incluso se ha podido seguir el progreso de las alteraciones por ellos provocadas. Un caso especialmente grave es el de Gurita I (fig. 18) donde hemos documentado durante más de un lustro el incremento de un desconchado que afecta a la cornamenta del gran ciervo.

Son, sin embargo, las acciones directamente protagonizadas por el ser humano las que provocan los efectos más devastadores sobre los petroglifos. La acción de la cantería tradicional durante los siglos XIX y XX, ha conllevado la extracción de grandes masas graníticas muchas de las cuales servían de soporte a los petroglifos. Éste es el caso de estaciones como A Picota (fig. 19) o Gurita IV, en la última de las cuales se han documentado varios motivos geométricos y naturalistas pero también los huecos dejados tras la extracción de dos cruces de piedra, una de las cuales permanece aún en el lugar por haberse fragmentado durante dicho proceso (fig. 20).

Una causa de alteración especialmente grave, por tratarse de un acto consciente y voluntario, es el vandalismo, patente en el repicado y/o pintado de los petroglifos. Existen en el Barbanza varios casos de este tipo de agresión como es el pintado de la estación de Campogrande I y, más recientemente, de Outeiro Campelos I y Gurita I. Dichas acciones sur- 


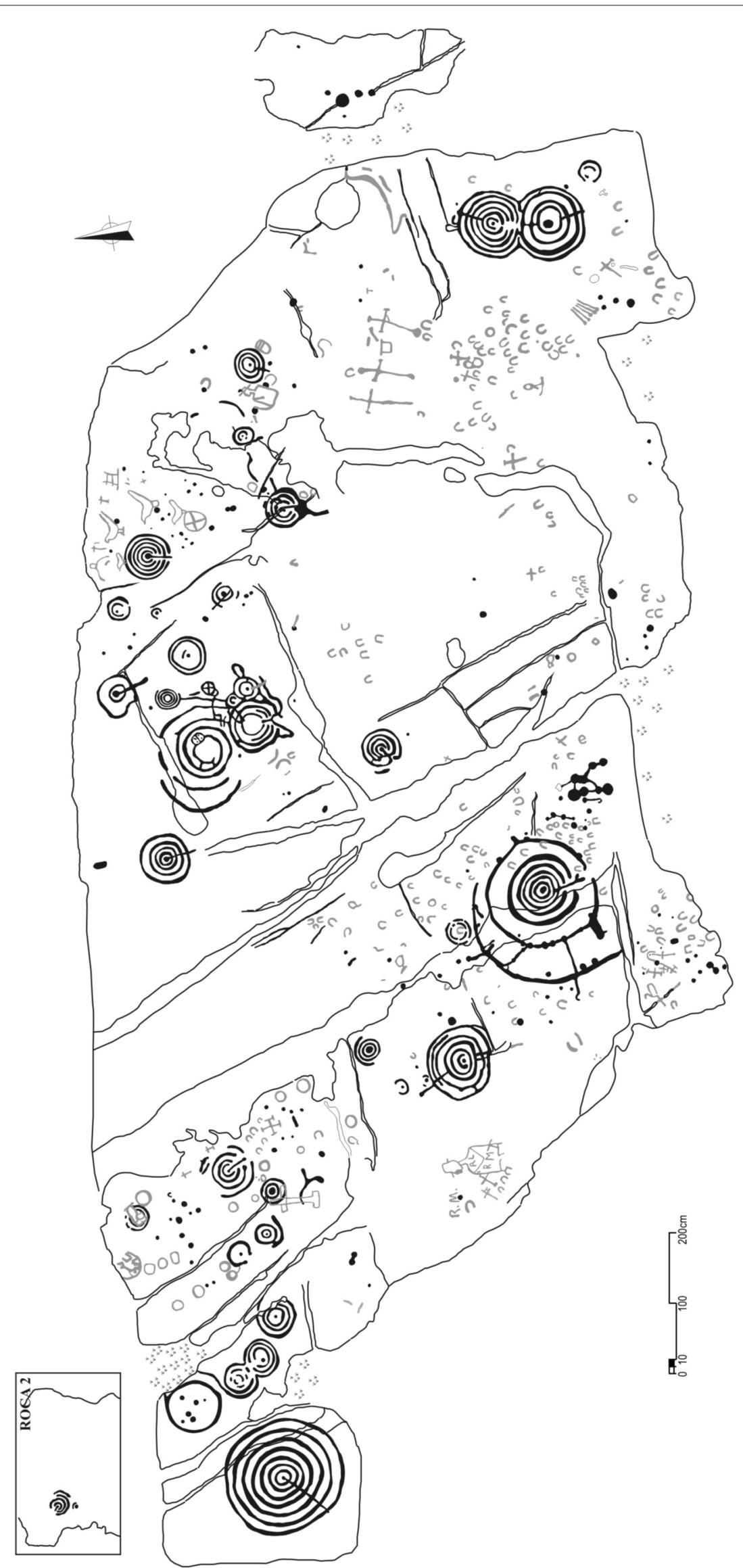

A Figura 22. Estación de Laxe Ferrada (Antas de Ulla, Lugo). 
gen, en buena parte de los casos, por la voluntad de observar los motivos con mayor claridad, pero también por el desconocimiento de los mismos. En consecuencia, creemos que, en un momento como el actual de creciente explotación turística del patrimonio arqueológico, la divulgación debe realizarse de un modo controlado y, sobre todo, enfatizando el papel de la educación y de la concienciación de la sociedad.

Desde un punto de vista arqueológico (o más bien antropológico) resultan especialmente interesantes determinadas alteraciones aplicadas de un modo intencional sobre alguna estación rupestre y que yendo más allá de una mera modificación física de la inscultura, parecen mostrar que ésta mantiene una carga simbólica que, en su caso, hay que neutralizar o bien rectificar, demostrando que, en ocasiones, el arte rupestre es un fenómeno que ha transcendido al tiempo de sus creadores originales. Resulta bastante habitual (aunque en modo alguno generalizado) encontrar indicios de cristianización de los paneles, mediante la inclusión de cruces $u$ otros motivos, como son los alfabetiformes. La cristianización (¿despaganización?) afecta de modo mayoritario (8 casos) a superficies con temas geométricos (cazoletas y combinaciones circulares), mientras que sólo en dos ocasiones hallamos cruciformes vinculados a figuras naturalistas. Esta circunstancia tal vez obedezca a la dificultad de "leer" y reconocer como de elaboración humana las segundas, lo que no sucede con el más reconocible grupo abstracto. En apo-

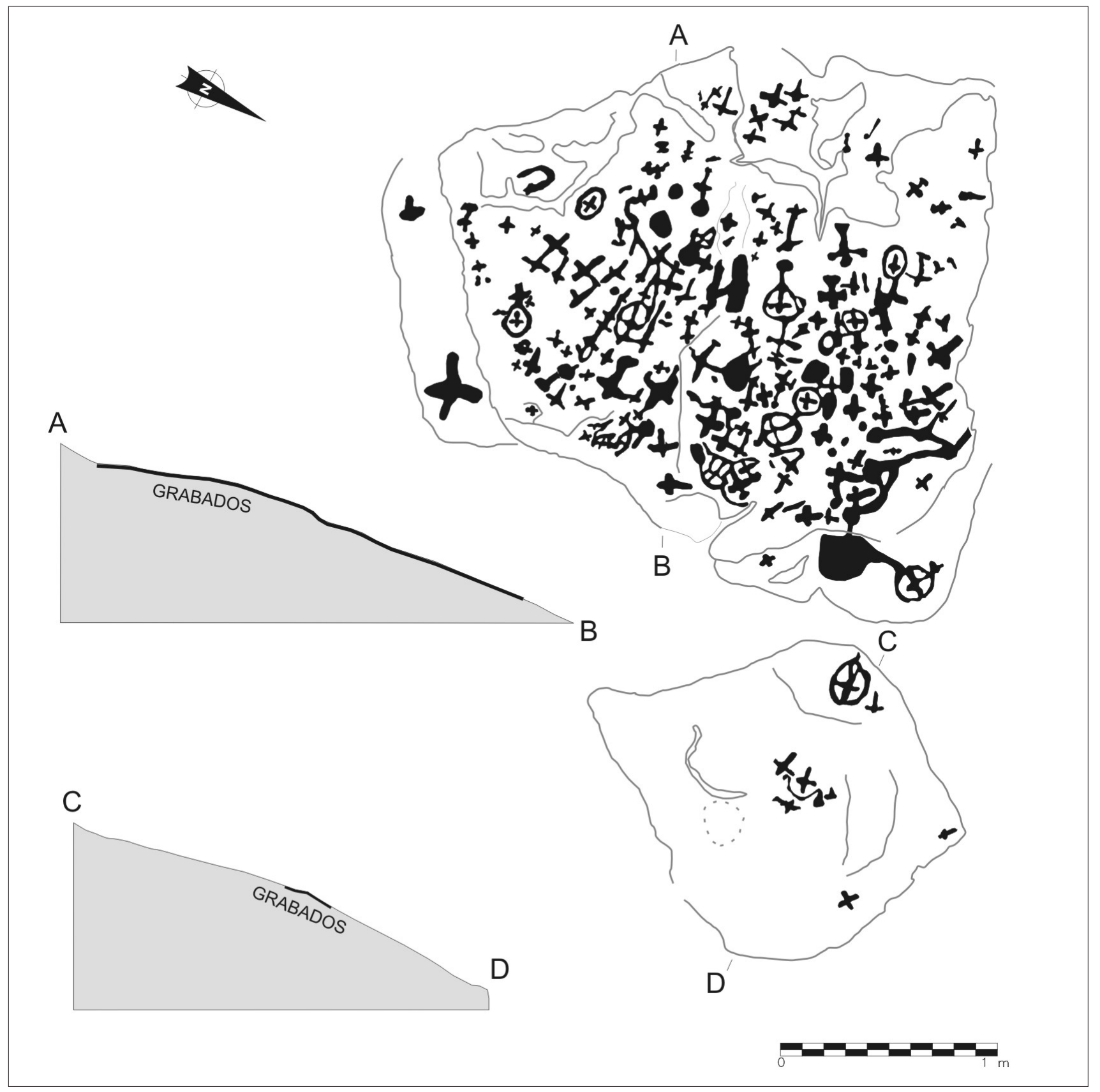

- Figura 23. Estación de Cruces de Loreto (Noal). 


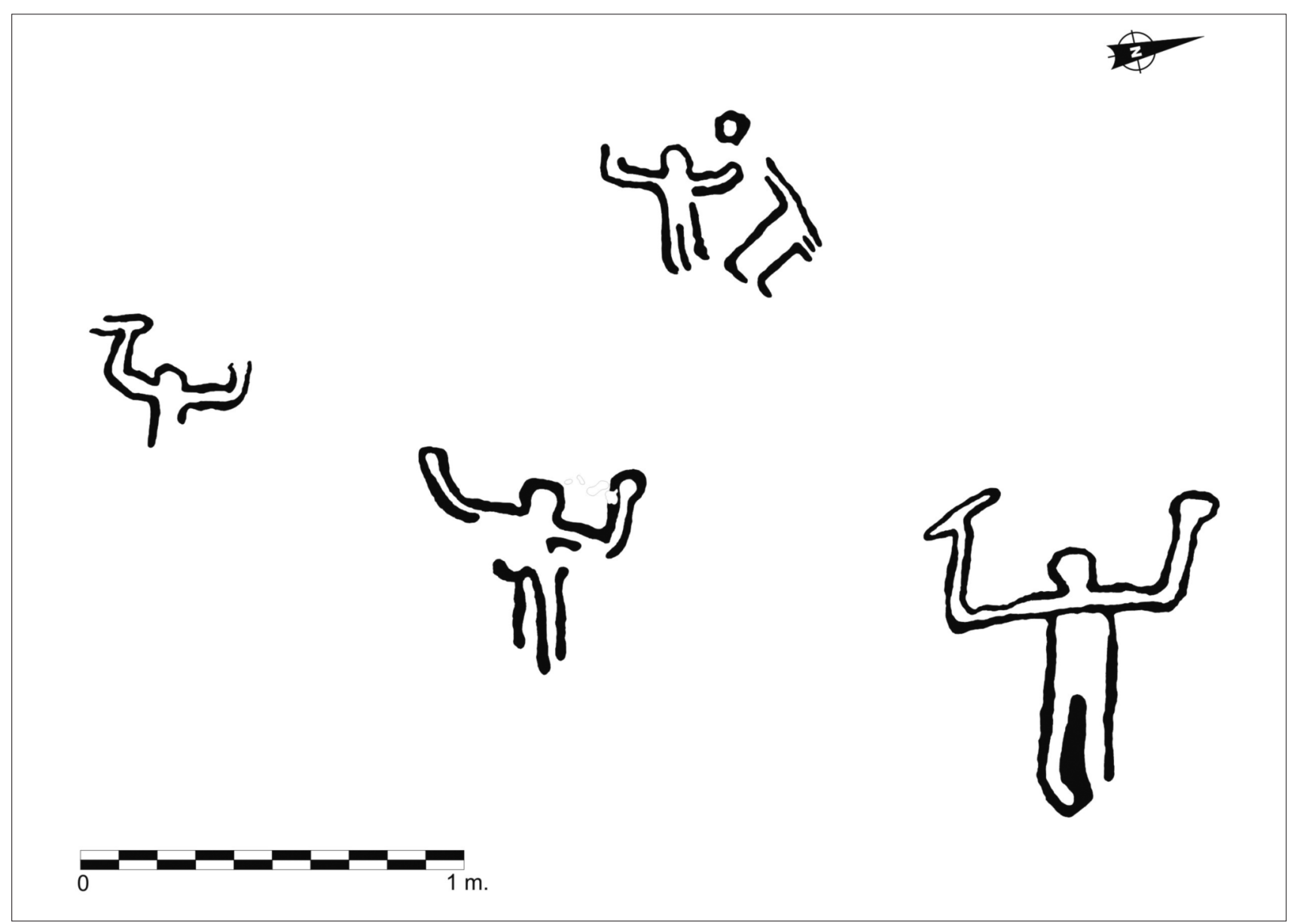

A Figura 24. Antropomorfos de Os Mouchos (Rianxo).

yo de nuestra hipótesis obra el hecho de que en entrevistas realizadas a canteros de la zona con mayor densidad de arte rupestre, la mayoría de los mismos no fuesen capaces de identificar la existencia de dichos motivos, incluso cuando muchos de ellos eran particularmente evidentes. En este sentido, no es sorprendente que la única destrucción deliberada y sistemática de un motivo concreto, afectase a una combinación circular en un panel particularmente abundante en esta clase de imágenes, perteneciente a la estación de Rego de Corzo (fig. 16).

Un caso peculiar de "revisión" afectó a la denominada Laxe da Sartaña, un gran panel con figuras naturalistas y también abstractas, que a mediados del siglo pasado fue intensamente grabado por un vecino, desvirtuando en gran medida las representaciones originales (Soto y Rey, 1994). Este mismo proceso también puede observarse en áreas del interior gallego, en donde se han documentado estaciones, como la de Laxe Ferrada (Antas de Ulla, Lugo) (Rodríguez et al., 2008) ampliamente alteradas en época histórica (fig. 22)

Existe una clara vinculación entre la presencia de cruciformes y la intención de remarcar la significación especial de un punto concreto del paisaje, incluso aunque no existan petroglifos en las inmediaciones. Un caso particularmente elocuente lo supone la estación de Cruces de Loreto, cerca de la iglesia del mismo nombre, en la cual se han documentado más de un centenar de cruces (fig. 23). El motivo de tal concentración de cruces no está claro, pues no parece que haya existido ningún grabado prehistórico en esa misma superficie (una roca esquistosa repleta de grietas y diaclasas), o en las inmediaciones, ni tampoco pueden ser consideradas como petroglifos de término, como sí ocurre con otros cruciformes aislados Por lo tanto, dichos grabados estaban señalizando un lugar de cierta importancia para el propio culto cristiano o bien intentando apropiarse de la significación que éste tenía en épocas anteriores al cristianismo y cuya naturaleza se nos escapa. Otro ejemplo de cristianización de un lugar más que de un yacimiento arqueológico lo supone $\mathrm{Ou}$ teiro Bicudo, situado a un centenar de metros de la iglesia de Baroña. Se trata de una gran roca granítica que, según las leyendas locales, fue transportada al lugar por una moura ${ }^{2}$. Como consecuencia parece haberse cristianizado el lugar con varias cruces, ignorando, sin embargo, el panel vertical con varios zoomorfos de grandes dimensiones que se encuentra situado al pie mismo de dicho afloramiento.

(2) Personaje mítico de la cultura popular gallega, en otras versiones la protagonista es una vieja. 


\section{BIBLIOGRAFÍA}

Agrafoxo Pérez, X. (1986): Prehistoria e Arqueoloxía da Terra da Barbanza. Concello de Noia.

Bouza Brey F. y López Cuevillas, F. (1927-1928): Prehistoria e Folklore da Barbanza. Nós, №47-52.

Concheiro Coello, A. y Gil Agra, D. (1994): Una nueva zona de Arte Rupestre al aire libre en el NW : La Península de Barbanza. Espacio, Tiempo y Forma, Madrid, I, 7, p. 127-144.

Fábregas ValCARCE, R. (2001): Los petroglifos y su contexto: un ejemplo de la Galicia meridional. Instituto de Estudios Viqueses. Vigo.

Fábregas Valcarce, R.; Guitián CAstromil, J.; Guitián Rivera, X. y Rodriguez RELLÁN, C. (2007): Un petroglifo de tipo Outeiro do Corno en Porto do Son (A Coruña). Gallaecia, 26, 55- 68. Santiago de Compostela.

Fábregas Valcarce, R. y Ruiz-Gálvez Priego, M. (1997): El Noroeste de la Península Ibérica en el Iller y $\|^{\circ}$ Milenios: propuestas para una síntesis. Saguntum, 30. 191-216.
Guitián CAstromil, J. y GuitiÁn Rivera, X. (2001): Arte Rupestre do Barbanza. Noia. Ed. Toxosoutos.

Mariño Del Río, M. (2000): Os Petroglifos de Porto do Son. Concello de Porto do Son.

SAntos Estévez, M. (2005): "Sobre la cronología del arte rupestre atlántico en Galicia". Artículo publicado en Arqueoweb (Revista Electrónica) 7(2), septiembre/diciembre 2005.

Soto Bareiro, M. J. y ReY CAStiñeIRAS, P. (1994): "Una metodoloxía de estudio para os petroglifos. Resultado en Laxe da Sartaña". Braña, 1, pp. 49-72.

Rodríguez RelLÁn, C.; Górgoso López, L. y Fábregas ValCARCE, R. (2008): 0 conxunto de petroglifos de Campo da Uz (Sta. María de Areas, Antas de Ulla) e as vías de tránsito cara o interior lucense. Gallecia, 27, 35-61. (Santiago de Compostela ).

Vilas, F., Sopeña, A.; Rey, L.; Ramos, A. Nombela, M. y ArChe, A., (1991): The Corrubedo beach-lagoon complex, Galicia, Spain: Dynamics, sediments and recent evolution of a mesotidal coastal embayment. Marine Geology, 97, pp. 391-404. 